\title{
Critical Thinking Instruction in English Reading Situation
}

\author{
Li-xia SHEN \\ Zhengzhou University of Science and Technology \\ No.1 Xueyuan Road, Erqi District, Zhengzhou City
}

\begin{abstract}
There some essential ideas on the clarification of conceptions of critical thinking, including the discussion on the alternatives to the concept of critical thinking, the definitions of critical thinking, and critical thinking model. The second topic focuses on critical thinking instruction. It includes a dispute on critical thinking instruction, various teaching approaches and strategies, and the assessment of critical thinking skills. The last topic is about critical thinking in English reading class. It mainly discussed the relationship between critical thinking and English reading, the effect of critical thinking on reading comprehension, and critical thinking instruction in English reading class.
\end{abstract}

\section{Keywords_critical thinking; instruction; reading situation}

\section{INTRODUCTION}

The intellectual root of critical thinking can be dated back to Socrates' practice in education in ancient Greece. Since then on, a great variety of ideas, principles and theories on critical thinking have been proposed. It is generally recognized that advancing students' critical thinking should be taken as a goal of higher education, and that critical thinking has been the quality sought by employers of university graduates. [1]Preparing students to be able to think critically is regarded significant in their social and professional lives. Educators and researchers agree that it is crucial for students to engage in critical thinking in academic instruction, because critical thinking can greatly contribute to students' success in their academic learning, and later in their daily and professional lives. [2] Employers and national educational policy are demanding that higher education ought to educate students into the qualified graduates who can think smartly and critically.

The first topic is about some essential ideas on the clarification of conceptions of critical thinking, including the discussion on the alternatives to the concept of critical thinking, the definitions of critical thinking, and critical thinking model. The second topic focuses on critical thinking instruction. It includes a dispute on critical thinking instruction, various teaching approaches and strategies, and the assessment of critical thinking skills. The last topic is about critical thinking in English reading class. It mainly discussed the relationship between critical thinking and English reading, the effect of critical thinking on reading comprehension, and critical thinking instruction in English reading class.

\section{THEORETICAL BACKGROUND: CRITICAL THINKING}

It is essential to find out the thread among variant arguments, conceptions and models which have been produced since critical thinking was initially drawn attention in pedagogical practice. This section provides a clear idea about the essence of critical thinking. It primarily emphasizes on conceptualization of critical thinking and critical thinking models. When researchers and educators set critical thinking as their research and education goals, they sometimes use other labels than critical thinking-higher order thinking, creative thinking, and problem solving. These labels are confusing, which can make trouble for theorists and practitioners, in particular, for those in critical thinking instruction. Therefore, for the theoretical and practical purposes, it is a fundamental step to clarify the subtle differences among these labels. The purification of these labels can contribute to the understanding of critical thinking and has some significant instructional implications for the present study.

\section{A. Higher Order Thinking}

It is not an easy research implementation for researchers to provide an abstract definition of higher order thinking. However, accessibly, higher order thinking can be discerned by its characterization. "Higher order thinking is difficult to define, however it can be easily recognized when it occurs". [3]Resnick argued that higher order thinking can be characterized as a non-algorithmic, complex and effortful mode of thinking which involves uncertainty, self-regulation, nuanced judgment, imposing meaning, and application of multiple criteria. Such thinking can produce "multiple solutions, each with cost and benefits rather than unique solution". [3] The discernable characteristics of higher order thinking when it occurs are, in essence, characterization of thinkers' externalized behaviors. In a broader and more abstract way, Newmann defined higher order thinking as "challenged and expanded use of mind" and lower order thinking as "represents routine, mechanistic application and limited use of the mind". [4] He explained that higher order thinking occurs when the student "interprets, analyzes, and manipulates information" and contrarily, lower order thinking involves "routine, mechanistic application of previously learned, memorized information". [4] Newmann claimed that his definition of higher order thinking is a broad conception rather than a specific conception such as critical thinking and informal reasoning. Lewis and Smith (1993) concurred that higher order thinking can be taken as an umbrella term including critical thinking, creative thinking, 
problem-solving and decision-making. They echoed the claim that higher order thinking can be recognized when it occurs, and offered the following definition of higher order thinking. "Higher order thinking occurs when a person takes new information and information stored in memory and interrelates and/or rearranges and extends this information to achieve a purpose or find possible answers in perplexing situations.'[5]

The delineation of higher order thinking by depicting its characteristics is not sufficient to draw an entire picture. Instantiated skills of higher order thinking constitute another half of the picture. Higher order thinking skills, in a degree, conform to level two through six of Bloom's taxonomycomprehension, application, analysis, synthesis, and evaluation. Newmann listed the skills which challenge students' mind. These skills include "scrutinizing arguments for logical consistency; distinguishing between relevant and irrelevant information and between factual claims and value judgments; using metaphor and analogy to represent problems and solutions; using rhetorical strategies such as stipulation of disputable claims to let an argument proceed; and implementing discussion strategies such as asking for clarification, pressing people to stay with an issue, and summarizing the progress of the conversation". [6]

Higher order thinking can occur whenever a person attempts to combine new information and previously memorized information to find a possible answer to a novel problem rather than recall of information previously learned in any situation. Comparing to critical thinking, higher order thinking can be stimulated in a more spacious arena by any other process of information than recall and memorization of information. Therefore, skills involved in such situations are larger than critical thinking. Ennis believed that, although critical thinking does not exhaust all higher order thinking skills, it incorporates a significant portion of higher order thinking. Paul thought that higher order levels of Bloom's taxonomy suggest that they make use of some basic concepts essential to critical thinking: inference, conclusion, evidence, premise, assumption, and the like. In a word, in terms of characteristics and skills, critical thinking is a component member of higher order thinking and encompassed under its conception, though there is considerable overlap between them.

\section{B. Creative Thinking}

Researchers tend to discuss creative thinking in comparison with critical thinking. Some view critical and creative thinking as two distinctive concepts. Critical thinking is analytic and evaluative, and seen as means for judgments within a given framework; while creative thinking is imaginative and inventive, and involves generating and inventing new ideas or solutions by transcending framework. Harris elaborated the differences between critical and creative thinking by listing the characteristics of two kinds of thinking. Critical thinking is analytic, convergent, vertical, focused, objective, verbal, linear, etc.; while creative thinking is generative, divergent, lateral, diffused, subjective, visual, associative, etc. Paul and Elder claimed that creative thinking is a process of producing, and critical thinking is a process of assessing.
Although admitting that there are considerable differences between critical and creative thinking, Harris believes that, in practical problem-solving, two kinds of thinking work together, and "are not really independent of each other". On the basis of review of previous research on fundamental difference between critical and creative thinking, Bailin rebutted that it is false to make a radical dichotomy between critical and creative thinking, because critical thinking can be imaginative and inventive in evaluation and judgment, and creative thinking analytic and judgmental in generating new products or ideas. In an activity such as making a judgment or solving a problem, "first, we must analyze the problem; then we must generate possible solutions; next we must choose and implement the best solution; and finally, we must evaluate the effectiveness of the solution". Therefore, it is exceedingly difficult to draw a clear-cut line between critical and creative thinking.

In defining critical thinking as "reasonable reflective thinking that is focused on deciding what to believe or do", [7] Ennis pointed out that creative thinking is covered under the definition and not excluded from it. Critical and creative thinking are interwoven. They thought that "critical thinking can be separated artificially, and that, in practical thought, they are one". [7] To be critical, creative acts are required such as evaluating a complex situation and possible solutions in an alternative way, formulating assumptions or hypotheses, and making a plan for investigation. In contrast, when new ideas or products are created, they need to be evaluated and judged for their quality and validity. It is a cyclical process from critical thinking to creative thinking, and then from creative thinking to critical thinking. There is an alternation between critical and creative thinking. Thinking can be analyzed and assessed, and as a result, strong thinking replaces weak thinking or stronger thinking replaces strong thinking. It is a process of incremental improvement of thinking. The outcomes of critical thinkingstrong thinking or stronger thinking require further analysis and assessment, and then, stronger and stronger thinking can be created, and should be assessed and evaluated repeatedly.

However, some dispute that critical thinking and problem solving should be treated as two differentiated concepts. "Critical thinking should not be considered comparable to problem solving", because critical thinking implies the evaluation of quality of thinking involved, while a problem can be solved critically or uncritically. Critical thinking and problem solving can lead to different outcomes and fulfill different goals. Beyer claimed that the two concepts serve different purposes, and that we need problem solving skills when we overcome "an obstacle to a preferred condition", while critical thinking aims to "ascertain the degree to which some phenomenon meets some criterion or the extent to which it is an authentic instance of a specifically defined phenomenon".[8] B. O. Smith treated critical thinking and problem solving as two different domains. One domain involves thinking related to assessment of arguments. One domain involves thinking related to problem solving.

Although critical thinking and problem solving serve different goals, and execute in different domains, the linkage between them cannot be ignored. Problem solving should not be regarded as designation of other kind of thinking in contrast with critical thinking. It should be seen as "arenas where 
critical thinking should take place". Critical thinking subsumes not only the assessment and evaluation of arguments but also the ability to identify a problem, to define and analyze the problem, to explore and evaluate alternative solutions, and to assess and evaluate the effect. In defining critical thinking as "reasonable reflective thinking that is focused on deciding on what to do or believe", Ennis noted that "acts such as formulating hypotheses, alternative ways of viewing a problem, question, possible solutions, and plans for investigating something, come under this definition". [7] Paul and Elder endorsed that critical thinking entails problem solving abilities.

Critical thinking is focused on assessment and evaluation of arguments, moreover, on analyses and evaluation of problems, and of solutions and effects. Critical thinking includes the abilities to analyze, synthesize and evaluate thinking or arguments, furthermore, the abilities to recognize problems, to describe the problem clearly and precisely, to collect, analyze, and interpret information needed to solve the problem, to evaluate variant options and determine the best ones as solutions, and to monitor the process of problem-solving and when necessary, revise the strategy used to solve the problem. Critical thinking, as encompassing term, includes problemsolving.

\section{The Proposed LABEL IN THE Present StUdy}

When higher order thinking occurs, it takes place in all the situations and involves all mental operations except memorization or recall of information. It is an umbrella concept including critical thinking and creative thinking, and in turn, problem solving. There is overlap between critical thinking and creative thinking, though the former focuses assessing and evaluating while the latter inventing and producing. It is not a linear roadmap from critical thinking to creative thinking, but a cyclical one for the purpose of incremental improvement of thinking. With respect to problem solving, the problem can be solved critically or creatively. It provides an arena where critical and creative thinking take place. Problem solving is not seen as a contrast with critical thinking or creative thinking, but, as component abilities, included in critical and creative thinking.

The present study places emphasize on the instruction of critical thinking skills, which are a component part of higher order thinking. Give the overlap between critical and creative thinking, critical thinking, as a label used in the present study, does not exclude creative thinking. New ideas or solutions produced and invented can be regarded as natural outcomes of critical thinking and used to verify whether students' critical thinking has been improved. In a cyclical process of critical and creative thinking, students' critical thinking can be enhanced. Problem solving ability, as a component part of critical thinking, is substantial for students to promote critical thinking. It can provide students with strong support when they confront with issues or problems in their study, life and work.

\section{CONCLUSION}

Since the idea of critical thinking intellectually was represented in the teaching practice and contemplation of a great philosopher of ancient Greece, Socrates, 2500 years ago, it has been a hardship for the researchers and theorists to reach a consensus on the exact conception of critical thinking. There are as many definitions of critical thinking as contemporary scholars who attempt to seek the clarification of definitions. The continuous endeavor to explicate the concept of critical thinking is undertaken under the assumption that it is conducive to the effective application of critical thinking in educational settings. However, the examination of various discourses on the concept of critical thinking shows that there is less disagreement among theorists on what is viewed to be the core of critical thinking than on how it is conceptualized narrowly and broadly within specific contexts and domains.

\section{REFERENCES}

[1] Fahim, Mansoor, \& Sa'eepour, Maryam. (2011). The impact of teaching critical thinking skills on reading comprehension of Iranian EFL learners. Journal of Language Teaching \& Research, 2(4), 867-874.

[2] Paul, R., \& Elder, L. (2008). The miniature guide to critical thinking: Concepts and tools. CA: The Foundation for Critical Thinking.

[3] Resnick, Lauren B. (1987). Education and learning to think. Washington, D. C.: National Academy Press.

[4] Newmann, Fred M. (1991). Promoting higher order thinking in social studies: Overview of a study of 16 high school departments. Theory \& Research in Social Education, 19(4), 324-340.

[5] Lewis, Arthur, \& Smith, David. (1993). Defining higher order thinking. Theory Into Practice, 32(3), 131-137.

[6] Bailin, S. (1998). Skills, generalizability and critical thinking. Paper presented at the Philosophy of education society of Great Britain: Conference papers 1998(pp. 259-267).

[7] Bailin, S., Case, R., Coombs, J. R., \& Daniels, L. B. (1999a). Common misconceptions of critical thinking. Journal of Curriculum Studies, 31(3), 269.

[8] Ennis, R. (1991). Critical Thinking A Streamlined Conception. Teaching Philosophy, 14(1), 5-27. 